Sharif University of Technology
Scientia Iranica
SCIENTIA
IRANICA
http://scientiairanica.sharif.edu

\title{
Reliability analysis of a vertical cut in unsaturated soil using sequential Gaussian simulation
}

\author{
A. Gholampour and A. Johari* \\ Department of Civil and Environmental Engineering, Shiraz University of Technology, Shiraz, 7194684471, Iran.
}

Received 29 July 2017; received in revised form 21 August 2017; accepted 23 October 2017

\author{
KEYWORDS \\ Vertical cut; \\ Reliability analysis; \\ Unsaturated soils; \\ Sequential Gaussian \\ simulation; \\ Conditional random \\ filed.
}

\begin{abstract}
This paper proposed a practical approach to reliability analysis of a vertical cut in unsaturated soil. This approach extends the application of the conditional random field to unsaturated soil. A real case study of a vertical cut was considered, and three boreholes were drilled to investigate the subsurface layers. The Sequential Gaussian Simulation (SGS) was used to generate a conditional random field considering the possible fluctuation of soil properties between known data. The undersampled parameters were estimated by the cokriging method, while the kriging method was used to estimate other stochastic parameters. In order to verify the efficiency of simulations, it was checked that all data were reproduced at their locations and the input semivariogram model was reproduced within acceptable fluctuations. To predict the unsaturated soil behavior, the Soil Water Retention Curve (SWRC) was estimated by the physico-empirical method with the aim of determining suction stress for finite element stability analysis. The vertical cut was analyzed with and without considering suction. It was concluded that considering unsaturated condition shifts the mean of safety factor from unsafe to safe ranges. It was illustrated that the number of known data affected the construction of conditional random fields and led to different probability levels of failure.

(C) 2019 Sharif University of Technology. All rights reserved.
\end{abstract}

\section{Introduction}

The stability of vertical excavations in soil is an important issue in geotechnical engineering and has become a common challenge amongst both theoreticians and practitioners. Excavations are typically carried out above the groundwater table, where the soils are unsaturated. In unsaturated soils, textural properties can affect the stability of excavations almost as much as mechanical properties. The soil properties involved in stability analysis imply many uncertainties though. The degree of uncertainty is influenced by both the lack

*. Corresponding author.

E-mail addresses: A.gholampour@sutech.ac.ir (A.

Gholampour); Johari@sutech.ac.ir (A. Johari)

doi: $10.24200 /$ sci. 2017.4571 of knowledge and the inherent spatial variability of the subsoil.

The importance of spatial correlation and local averaging of statistical geotechnical properties has been recognized by some investigators [1]. Starting in the early 90s, a new technique called Random Finite Element Method (RFEM) was developed for probabilistic geotechnical engineering [2]. In this method, unconditional random field theory is combined with the Finite Element Method (FEM), and only the statistics of limited site investigation data, such as means, standard deviations, and autocorrelation distances, are utilized in calculations.

By using random field methodology, the influence of spatial variability of soil properties on the stability problems has been investigated for different soil conditions. For example, Griffiths and Fenton [3] studied the probability of failure of a cohesive slope. It 
was concluded that simplified probabilistic analysis, in which spatial variability was ignored due to assuming perfect correlation, could lead to unconservative estimates of the probability of failure. Szynakiewicz et al. [4] investigated the stability of drained slope within both deterministic and probabilistic contexts. Their results corresponded to the fact that how the spatial variability of the respective properties could affect the probability of failure in a probabilistic slope analysis.

The uncertainties of hydraulic property parameters for unsaturated soils and their effects on the reliability of slopes under rainfall condition have also been studied by a number of researchers. For example, Chong et al. [5] considered the effect of the uncertainty of each parameter in the SWRC and the permeability function on the safety factor of unsaturated soil slopes using Monte Carlo Simulation (MCS). Tung and Chan [6] performed a probabilistic analysis of rainfall infiltration and slope stability considering uncertainties in SWRCs. Arnold and Hicks [7,8] analyzed the effect of spatial variability of matric suction on unsaturated slope stability under steady-state conditions. In all previous studies, the unsaturated soil behavior was modeled by solving equations based on flow laws for air and water phases during the infiltration or evaporation process. However, there is no accurate approach for calculating suction in a static equilibrium condition, especially when the water table is far below the surface.

In spite of great achievements in the context of reliability analysis for spatially variable soils, the traditional unconditional random field uses only the statistics such as mean, standard deviation, and autocorrelation distance of limited site investigation data and discards the actual data. Site investigation data generally exist in an engineering project, even though the amount of data may not be excessive. These data reflect the true values of the soil properties at certain locations, which should remain invariant in each random field simulation. Neglecting the known data increases the simulation variance of random fields and can result in an unconservative design, representing a waste of site investigation effort. On the other hand, the conditional approach takes full advantage of the available data which, in turn, minimizes the level of uncertainty.

Stability analysis based on the conditional random field has not received enough attention in the literature, and only few studies have addressed it. Kim and Sitar [9] investigated the effect of a specific number of cored samples on the probability of slope failure. Liu et al. [10] evaluated the reliability of a slope in spatially variable soils while considering the known data at particular locations. Although they both used conditional simulation in stability analysis, cross-correlation was not considered in their studies, meaning that only univariate interpolation was carried out in random field simulation. Besides, in both studies, a homogenous soil slope was analyzed by the limit equilibrium method, discarding the soil saturated/unsaturated conditions.

The main aim of this paper is to present a practical approach to reliability analysis of an unsaturated vertical cut using SGS. The analyses were carried out by a coded program to determine the effect of spatial variability of soil properties through geostatistical methods, which are powerful tools for estimating the soil property values in non-sampled areas. For this purpose, a real unsaturated vertical cut was considered under a static equilibrium condition, and the SWRC estimation's parameters and the main mechanical soils' properties were inserted between the known data based on geostatistical techniques. First, stability analysis was performed deterministically and, then, extended to probabilistic context. Eventually, the probability density function (pdf) of Factor of Safety (FS) was obtained; then, the probability of failure and reliability index were determined. In order to assess the effects of soil suction in reliability analysis, vertical cut stability was conducted with and without considering suction, and the cumulative distribution functions (cdf) of these two different conditions were compared. In another part of this paper, the effect of the number of boreholes on reliability analysis was investigated, and different cases were studied.

\section{Modeling of unsaturated condition}

An optimized design of many geotechnical problems, such as vertical cuts above water table, is based on the shear strength of unsaturated soil. Unsaturated soil's shear strength may be determined directly in the laboratory $[11,12]$ or indirectly by the developed models. The indirect methods can be categorized into two major groups; in the first group, the models were developed by considering two independent state variables, namely suction, $S_{u}$, and mean net stress, $P$. The model proposed by Fredlund et al. [13] as given below falls in this category.

$$
\tau=c^{\prime}+S_{u} \tan \varphi^{b}+P \tan \varphi^{\prime},
$$

where $\tau$ is the shear strength, $\varphi^{b}$ is the angle of shearing resistance with respect to suction, and $c^{\prime}$ and $\varphi^{\prime}$ are effective cohesion and effective friction angle, respectively.

The second group includes effective stress-based methods. In these methods, the shear strength is simply expressed in terms of the effective stress by:

$$
\tau_{f}=c^{\prime}+\sigma^{\prime} \tan \varphi^{\prime},
$$

where $\sigma^{\prime}$ is the effective normal stress. In unsaturated soils, all mechanical aspects such as volume change and shear strength are governed by effective stress. A 
wide variety of attempts have been made to develop a concept for effective stress in unsaturated soil [1416]. Among all these studies, Bishop [17] formulation, which is widely cited and is basically the expanded form of Terzaghi's classical effective stress theory, was used in this paper, too. The equation is given by:

$$
\sigma^{\prime}=\left(\sigma-u_{a}\right)+\chi\left(u_{a}-u_{w}\right)
$$

where $\sigma$ is the total stress, $u_{a}$ is the pore air pressure, and $u_{w}$ is the pore water pressure. The term $\left(u_{a}-u_{w}\right)$ is called matric suction, and $\chi$ represents the effective stress parameter.

There is still an ongoing discussion regarding the definition of $\chi$, since it cannot be measured directly. Amongst numerous existing empirical equations [1820], the one proposed by Vanapalli et al. [21] in most cases has shown an appropriate estimate of the effective stress parameter. The equation is presented as follows:

$$
\chi=\frac{\theta_{w}-\theta_{r}}{\theta_{s}-\theta_{r}}
$$

where $\theta_{w}$ is the water content in the considered matric suction, $\theta_{s}$ is the saturated water content, and $\theta_{r}$ is the residual water content. According to Eq. (3), it is clear that the calculation of $\chi$ and $\left(u_{a}-u_{w}\right)$ is the main task in determining unsaturated soils' effective stress. While $\chi$ can be determined by different proposed models such as the model of Vanapalli et al. [21], the determination of soil suction depends on water flow state in unsaturated soils.

\subsection{Estimation of suction using physico-empirical method}

When there is a flow in unsaturated soil, water and air tend to follow a relatively tortuous flow pass during the infiltration or evaporation process. In this condition, the suction head in different soil depths is computed by solving equations based on flow laws for air and water phases. Scientists have developed a good comprehension of the role of flow laws in saturated/unsaturated stability problems [22-24]. In this situation, rainfall and runoff play an important role in modeling and analysis. Hence, a great deal of research has been assigned to the prediction of daily or annual rainfall and runoff [25-27].

On the other hand, when there is no considerable flow of water from the ground surface and also the air flow is very insignificant in the unsaturated area, the pore water pressures will be negative. This negative pore water pressure head, which is conventionally known as the matric suction, causes the shear strength to increase.

When the hydraulic head is zero within the soil profile (i.e., static equilibrium condition), there is an alternative approach to estimating the matric suction by virtue of using SWRC. The soil water retention curve represents the amount of water contained in the pores at a given soil suction, and it is a key factor in the prediction of unsaturated soils behavior. There are several methods presented to obtain the SWRC for the particular soil. However, high timeconsumption and excessive cost associated with laboratory and field procedures encourage researchers to use empirical methods. There is also much more essential information available to use in these techniques.

The empirical methods can be categorized into four major groups. In the first group, water content at each suction value correlates with specific soil properties such as D10 (sieve size for $10 \%$ passing) and porosity. This process generally requires a regression analysis followed by a curve fitting procedure [28]. The second group includes methods that correlate parameters of an analytical equation with basic soil properties such as Grain Size Distribution (GSD) and dry density using regression analysis [29]. The third group is based on physic-empirical modeling of SWRC. This approach converts the GSD into a Pore Size Distribution (PSD), which in turn is related to a distribution of water content and associated pore pressure [30-32]. Artificial intelligence methods, such as neural network and genetic programming, and other machine learning methods fall into the fourth group [33-34].

Among physico-empirical methods [30-32], the model of Arya et al. [35] dominated the unsaturated zone application. This method is implemented in this study due to its reasonable predictive ability and more available textural input data. In the following, pertinent aspects of the model are reviewed.

At the outset, the GSD data fit the unimodal equation of Fredlund et al. [36] to obtain a continuous curve. The mathematical equation can be used as the basis for the analysis associated with estimating the SWRC, and a method is provided for representing the entire curve between measured data points. The equation is given by:

$$
\begin{aligned}
P_{p}(d)= & \frac{1}{\operatorname{In}\left[\exp (1)+\left(\frac{a_{g r}}{d}\right)^{n_{g r}}\right]^{m_{g r}}} \\
& \left\{1-\left[\frac{\operatorname{In}\left(1+\frac{d_{r}}{d}\right)}{\operatorname{In}\left(1+\frac{d_{r}}{d_{m}}\right)}\right]^{7}\right\},
\end{aligned}
$$

where $P_{p}(d)$ is the percent passing of particular grain size, $d ; a_{g r}, n_{g r}$, and $m_{g r}$ are the fitting parameters corresponding to the initial break, the maximum slope, and the curvature of the grain size curve, respectively; $d_{r}$ is the parameter related to the amount of fines in soil; and $d_{m}$ is the diameter of the minimum allowable size particle.

To begin with the model of Arya et al. [35], the 
obtained GSD curve is divided into $n$ size fractions, and the solid mass in each fraction is assembled to form a hypothetical, cubic close-packed structure consisting of uniform size spherical particles. To determine the water content associated with each fraction, $\theta_{i}$, the water-filled pore volumes must be added successively as follows:

$$
\theta_{i}=\left(\varphi S_{w}\right) \sum_{j=1}^{i} w_{i}, \quad i=1,2, \ldots, n,
$$

where $w_{i}$ is the fraction solid mass; $S_{w}$ is the ratio of the measured saturated water content to the theoretical porosity; and $\varphi$ is the total porosity that can be calculated from void ratio $(e)$ as follows:

$$
\varphi=e /(1+e) \text {. }
$$

On the other hand, the theoretical porosity can be estimated by assembled pore volume. The pore volume associated with the solid mass in the $i$ th particle size fraction $\left(V_{p i}\right)$ is represented as a single cylindrical tube, which can be calculated by:

$$
V_{p i}=\left(w_{i} / \rho_{p}\right) e
$$

To determine the head pressure value $\left(h_{i}\right)$ related to each water content, the capillary equation can be used as follows:

$$
h_{i}=\frac{2 \gamma \cos \Theta}{\rho_{w} g r_{i}}
$$

where $\gamma$ is the surface tension at the air-water interface; $\Theta$ is the contact angle; $\rho w$ is the density of water; $g$ is the acceleration due to gravity; and $r_{i}$ is the pore radius. For a natural soil, the pore radius is related to particle radius by:

$$
r_{i}=0.816 R_{i} \sqrt{e n_{i}^{(1-\alpha)}}
$$

where $R_{i}$ is the mean particle radius for the $i$ th particle fraction, $\alpha$ is the scaling factor, and $n_{i}$ is the number of spherical particles that can be calculated for each fraction of GSD as follows:

$$
n_{i}=\frac{3 w_{i}}{4 \pi \rho_{p} R_{i}^{3}} .
$$

After determining the SWRC, the suction value at each point was obtained by corresponding water content value. Then, the effective stress parameter $(\chi)$ was directly determined by Eq. (4) and the method proposed by Zhai and Rahardjo [37] for determining SWRC variables (e.g., saturated and residual water contents). The SWRC variables can also be determined by the graphical methods; however, these methods are subjective and time consuming. In the end, the suction stress was calculated as a product of suction value and effective stress parameter and was substituted into the shear strength of unsaturated soil.

\section{Geostatistical analysis}

The inherent variability of the soil parameters dictates that the stability problems are of a probabilistic nature rather than being deterministic. Moreover, in-situ tests, in particular, provide a good characterization of soil properties at the location where tests are performed; however, inevitable uncertainty remains at locations that are not examined.

As a solution, geostatistical approaches have been applied in geotechnical engineering for assessing the effect of uncertainties in geotechnical predictions and quantifying the spatial variability of physical and mechanical soil properties. The purpose of using the geostatistical technique is to provide the best univariate and multivariate estimations of the soil properties between the known data. The well-established kriging method is used as a univariate geostatistical tool to perform spatial interpolation between the known borehole data. On the other hand, if the sample properties are themselves correlated, then the cokriging method is applied to perform multivariate analysis.

The geostatistical analysis is not complete unless the degree of fluctuation in variables between sample points is assessed. For this purpose, conditional simulation techniques, such as SGS, are used to estimate the possible fluctuation of the variables in the domain of interest. In the following, required geostatistical concepts are presented in order to conduct the sequential Gaussian simulation.

\subsection{Semivariogram analysis}

The first step in the geostatistical analysis is to estimate semivariogram. The semivariogram shows how the dissimilarity between random functions $Z(x)$ and $Z(x+h)$ evolves with the separation of $h$. For a set of data $Z\left(x_{i}\right), i=1,2, \ldots$, the experimental semivariogram is computed as follows:

$$
\gamma_{j j}(h)=\frac{1}{2 N_{j j}(h)} \sum_{i=1}^{N(h)}\left[Z_{j}\left(x_{i}\right)-Z_{j}\left(x_{i}+h\right)\right]^{2},
$$

where $\gamma_{j j}(h)$ is the experimental semivariogram, and $N_{j j}(h)$ is the number of pairs of data points separated by the particular lag vector, $h$.

In the multivariate geostatistical analysis, the spatial structure of a pair of cross-correlated variables is described by the cross-semivariogram. The experimental cross-semivariogram for random functions $Z_{j}(x)$ and $Z_{k}(x)$ is computed using the following equation:

$$
\begin{aligned}
& \gamma_{j k}(h)=\frac{1}{2 N_{j k}(h)} \sum_{i=1}^{N(h)} \\
& \quad\left\{\left[Z_{j}\left(x_{i}\right)-Z_{j}\left(x_{i}+h\right)\right]\left[Z_{k}\left(x_{i}\right)-Z_{k}\left(x_{i}+h\right)\right]\right\},
\end{aligned}
$$




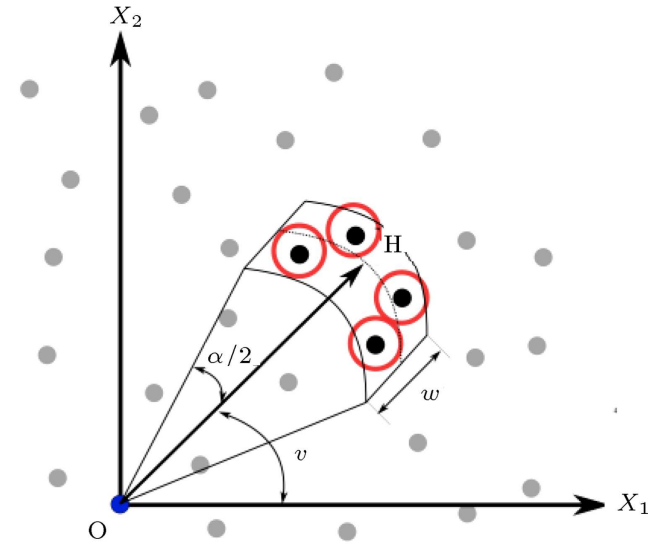

Figure 1. The geometry for discretizing the lag into bins by distance and direction.

where $\gamma_{j k}(h)$ is the experimental cross-semivariogram, and $N_{j k}(h)$ is the number of pairs of data points, separated by $h$, which have measured values of both random functions $Z_{j}(x)$ and $Z_{k}(x)$.

To obtain experimental semivariogram containing directional information, the separations must be grouped in terms of direction and distance. Figure 1 shows the geometry of the grouping. In the figure, $w$ is the range of distances. The nominal lag distance is represented by line $\mathrm{OH}$ of length $h$. A set of directions is chosen, one of which includes $v$ and the range of directions, $\alpha$, such that $\alpha=\pi / n$, where $n$ is the number of directions and $v$ progresses in steps of $\alpha$ from 0 to $\pi /(n-1)$. Then, for a point $x_{i}$ at $O$ with the second point $x_{i}+h$ within the stippled zone, $\left\{Z\left(x_{i}\right)-Z\left(x_{i}+h\right)\right\}$ contributes to $\gamma(h)=\gamma(h, v)$. More details about the determination of experimental semivariograms can be found in the study of Journel and Huijbregts [38].

The experimental semivariograms are replaced by a fitted mathematical function as a model or approximation of the theoretical semivariograms to have a physical meaning. This mathematical function can be described with three terms: a nugget effect ' $C_{0}$ ', a sill ' $S$ ', and a range ' $A$ '. These parameters are obtained through the fitting process. There are many algorithms in the literature, such as nonlinear least squares algorithm, for fitting the authorized model to the experimental semivariogram [39].

\subsection{Kriging and cokriging interpolation}

Interpolation is the estimation of values in an area for points that have not actually been sampled. There are many different interpolation techniques, ranging from simple linear techniques that average the values of nearby sampled points to more complex techniques, such as kriging or cokriging, which are used in the average weights based on the distance to nearby sample points and the degree of autocorrelation for those distances.

The kriging method was developed during the
1960 s and 1970s [40,41]. In this technique, interpolation estimates are based on values at neighboring locations plus knowledge about the underlying spatial relationships in a dataset. Semivariograms provide knowledge about the underlying relationships. The application of this interpolation technique produces the best, linear unbiased estimate of the random function between the known data.

Depending on the properties of the random function and various degrees of stationarity assumed, simple, ordinary, and universal methods can be used. In this paper, the global means of variables are assumed to be unknown. Hence, the ordinary kriging method was performed to interpolate variables between the known data. For an unknown field point, $x_{0}$, ordinary Kriging estimator, $Z^{*}\left(x_{0}\right)$, based on the known data $Z\left(x_{i}\right), i=1,2, \ldots, N$, is defined as the linear unbiased estimator:

$$
Z^{*}\left(x_{0}\right)=\sum_{i=1}^{N} \lambda_{i} Z\left(x_{i}\right),
$$

where $\gamma$ is the ordinary kriging coefficient, which is determined by solving the ordinary kriging system as follows:

$$
\Lambda \Gamma=\gamma
$$

The unknown and right-hand side of Eq. (15) are given, respectively, by the following:

$$
\begin{gathered}
\boldsymbol{\Gamma}=\left[\begin{array}{c}
\lambda_{1} \\
\lambda_{1} \\
\vdots \\
\lambda_{N} \\
\beta_{O K}
\end{array}\right] \\
\gamma=\left[\begin{array}{c}
\gamma\left(x_{0}, x_{1}\right) \\
\gamma\left(x_{0}, x_{2}\right) \\
\vdots \\
\gamma\left(x_{0}, x_{N}\right) \\
1
\end{array}\right],
\end{gathered}
$$

where $\beta_{O K}$ is the Lagrangian parameter, and $\gamma\left(x_{0}, x_{i}\right), i=1,2, . ., N$ is the semivariogram between unknown point $x_{0}$ and data point $x_{i}$. The ordinary Kriging matrix system is defined by:

$\boldsymbol{\Lambda}=\left[\begin{array}{ccccc}\gamma\left(x_{1}, x_{1}\right) & \gamma\left(x_{1}, x_{2}\right) & \cdots & \gamma\left(x_{1}, x_{N}\right) & 1 \\ \gamma\left(x_{2}, x_{1}\right) & \gamma\left(x_{2}, x_{2}\right) & \cdots & \gamma\left(x_{2}, x_{N}\right) & 1 \\ \vdots & \vdots & \ddots & \vdots & \vdots \\ \gamma\left(x_{N}, x_{1}\right) & \gamma\left(x_{N}, x_{2}\right) & \cdots & \gamma\left(x_{N}, x_{N}\right) & 1 \\ 1 & 1 & \cdots & 1 & 0\end{array}\right]$ 
where $\gamma\left(x_{i}, x_{j}\right), i, j=1,2, . ., N$, are the semivariograms between $N$ data points. The estimation variance of ordinary kriging is:

$$
\sigma_{O K}^{2}=\beta_{O K}-\gamma\left(x_{0}, x_{0}\right)+\sum_{i=1}^{N} \lambda_{i} \gamma\left(x_{i}, x_{0}\right) .
$$

Cokriging is the multivariate extension of kriging to several variables whereby several variables are estimated jointly, utilizing the best linear unbiased estimator. Cokriging is applied in situations where there is a cross-correlation between regionalized variables, and one or more of the regionalized variables are undersampled.

Undersampling means that the main variable to be estimated is sampled less intensely than the others, usually, at a subset of the sampling points. In this case, the spatial correlation between the other variables and their relation to the main variable add information that is lacking with regard to the main variable alone. Between correlated variables $V$, the linear ordinary cokriging estimator for variable $u$ at an unknown field point $x_{0}$ is as follows [42]:

$$
Z_{u}^{*}\left(x_{0}\right)=\sum_{l=1}^{V} \sum_{i=1}^{n_{l}} \lambda_{i l} Z_{i}\left(x_{i}\right)
$$

where $Z^{*}$ and $Z$ are, respectively, denoted by the estimated and measured values of the considered variable. Subscript $i$ represents $n_{l}$ locations, in which variable $l$ is measured; $\lambda_{i l}$ represents the cokriging weights, which are determined by solving the ordinary cokriging system as in the following:

$$
U Y=D
$$

Here, for two variables, $u$ and $v$, the cokriging system is presented in the matrix form:

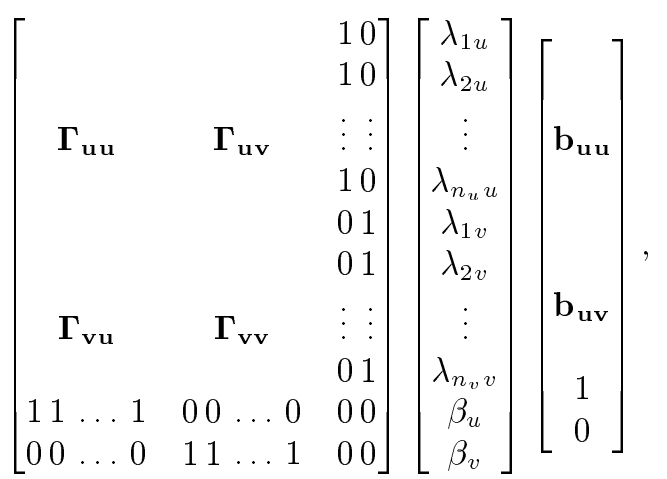

where $\beta_{u}$ and $\beta_{v}$ are Lagrange multipliers. $\boldsymbol{\Gamma}_{\mathbf{u v}}$ denotes a matrix of semivariograms (including crosssemivariograms where $u \neq v$ ) between sampling points in a neighborhood. For example, if there are $n_{u}$ places in which variable $u$ is measured and $n_{v}$ places where $\nu$ is measured, the order of the matrix is $n_{u} \times n_{v}$ :
$\Gamma_{\mathbf{u v}}=$

$$
\left[\begin{array}{cccc}
\gamma_{v u}\left(x_{1}, x_{1}\right) & \gamma_{u v}\left(x_{1}, x_{2}\right) & \ldots & \gamma_{u v}\left(x_{1}, x_{n_{v}}\right) \\
\gamma_{u v}\left(x_{2}, x_{1}\right) & \gamma_{u v}\left(x_{2}, x_{2}\right) & \ldots & \gamma_{u v}\left(x_{2}, x_{n_{v}}\right) \\
\vdots & \vdots & \ddots & \vdots \\
\gamma_{u v}\left(x_{n_{u}}, x_{1}\right) & \gamma_{u v}\left(x_{n_{u}}, x_{2}\right) & \ldots & \gamma_{u v}\left(x_{n_{u}}, x_{n_{v}}\right)
\end{array}\right](23)
$$

The vectors of semivariograms and cross-semi- variograms for variable $u$ are denoted by $\mathbf{b}_{\mathbf{u u}}$ and $\mathbf{b}_{\mathbf{u v}}$, respectively, in the following matrix form:

$$
\mathbf{b}_{\mathbf{u u}}=\left[\begin{array}{c}
\gamma_{u u}\left(x_{1}, x_{0}\right) \\
\gamma_{u u}\left(x_{2}, x_{0}\right) \\
\vdots \\
\gamma_{u u}\left(x_{n_{u}}, x_{0}\right)
\end{array}\right], \quad \mathbf{b}_{\mathbf{u v}}=\left[\begin{array}{c}
\gamma_{u v}\left(x_{1}, x_{0}\right) \\
\gamma_{u v}\left(x_{1}, x_{0}\right) \\
\vdots \\
\gamma_{u v}\left(x_{n_{v}}, x_{0}\right)
\end{array}\right]
$$

where $\gamma_{u u}$ and $\gamma_{u v}$ are the direct and cross semivariograms, respectively. The minimized cokriging estimation variance is:

$$
\sigma_{C K}^{2}=\sum_{l=1}^{V} \sum_{j=1}^{n l} \lambda_{j l} \gamma\left(x_{j}, x_{0}\right)+\beta_{u}-\gamma_{u u}\left(x_{0}, x_{0}\right) .
$$

There are other interpolation methods such as Inverse Distance Weighting (IDW) and Normal Distance Weighting (NDW), in which interpolation estimates are made based on values at nearby locations and weighted only by distance from the interpolation location. However, neither IDW nor NDW makes assumptions about spatial relationships.

\subsection{Sequential Gaussian simulation}

The values obtained by the kriging or cokriging system are predicted with minimized estimation variance and, therefore, show lower fluctuation than the actual, unknown values [38]. Hence, conditional simulation models are used to reproduce the actual statistics, maintain the texture of the variation, and take precedence over local accuracy. Unconditional simulation is simply the application of the general Monte Carlo technique whereby values are created with a particular covariance or semivariogram functions. However, in conditional simulation, in addition to creating possible values of random variables elsewhere, the generator must return the data values to known places.

Conditional simulation techniques can be categorized into direct and indirect approaches. Indirect approaches are based on unconditional simulation, which is transformed to the conditional ones [43]. These approaches are used when the mean and variance are known and constant over the region of interest. However, direct approaches, such as SGS, are used when the mean and variance are unknown or variable. In this study, it was assumed that the mean does not stabilize and the variance always increases over 
increasingly large domains, which opened up a wider field of application. Hence, the SGS method was implemented to perform conditional simulations.

The sequential Gaussian simulation is the most straightforward algorithm for generating a realization of a multivariate Gaussian field. In this technique, each variable is simulated sequentially according to its normal conditional cumulative distribution function (ccdf) through a kriging or cokriging estimation system. The basic conditional sequential simulation steps are mentioned as follows [40]:

1. Define a random path which meets all nodes of the grid in each realization;

2. Define a search ellipsoid for each grid node to find the adjacent known data;

3. Use kriging/cokriging with a semivariogram model to determine the mean and variance of ccdf;

4. Draw a value from the ccdf of the random variable;

5. Add this new value to the initial conditioning dataset;

6. Repeat until all nodes are simulated.

As is discussed by Dowd [44], the SGS method has several advantages including automatic handling of anisotropies, data conditioning, and fast computer implementation since an efficient kriging/cokriging algorithm with a moving neighborhood search capability is all that is required.

\section{Implementation procedure of reliability analysis}

In the previous sections, the methodologies for estimating the suction and generating conditional simulations were introduced. The main focus in this section is on the practical implementation of the proposed reliability analysis for a vertical cut in unsaturated soil. The implementation procedure is schematically shown in Figure 2. In general, the whole procedure consists of three parts repeated by the application of the general Monte Carlo technique: generation of the conditional random fields, estimation of shear strength, and implementation of stability analysis. A detailed description of the proposed reliability analysis is given as follows:

Step 1. Collect the measured data and discretize the domain into finite elements in which the mesh involves the known data of boreholes (the same mesh was used for conditional simulation and finite element analysis);

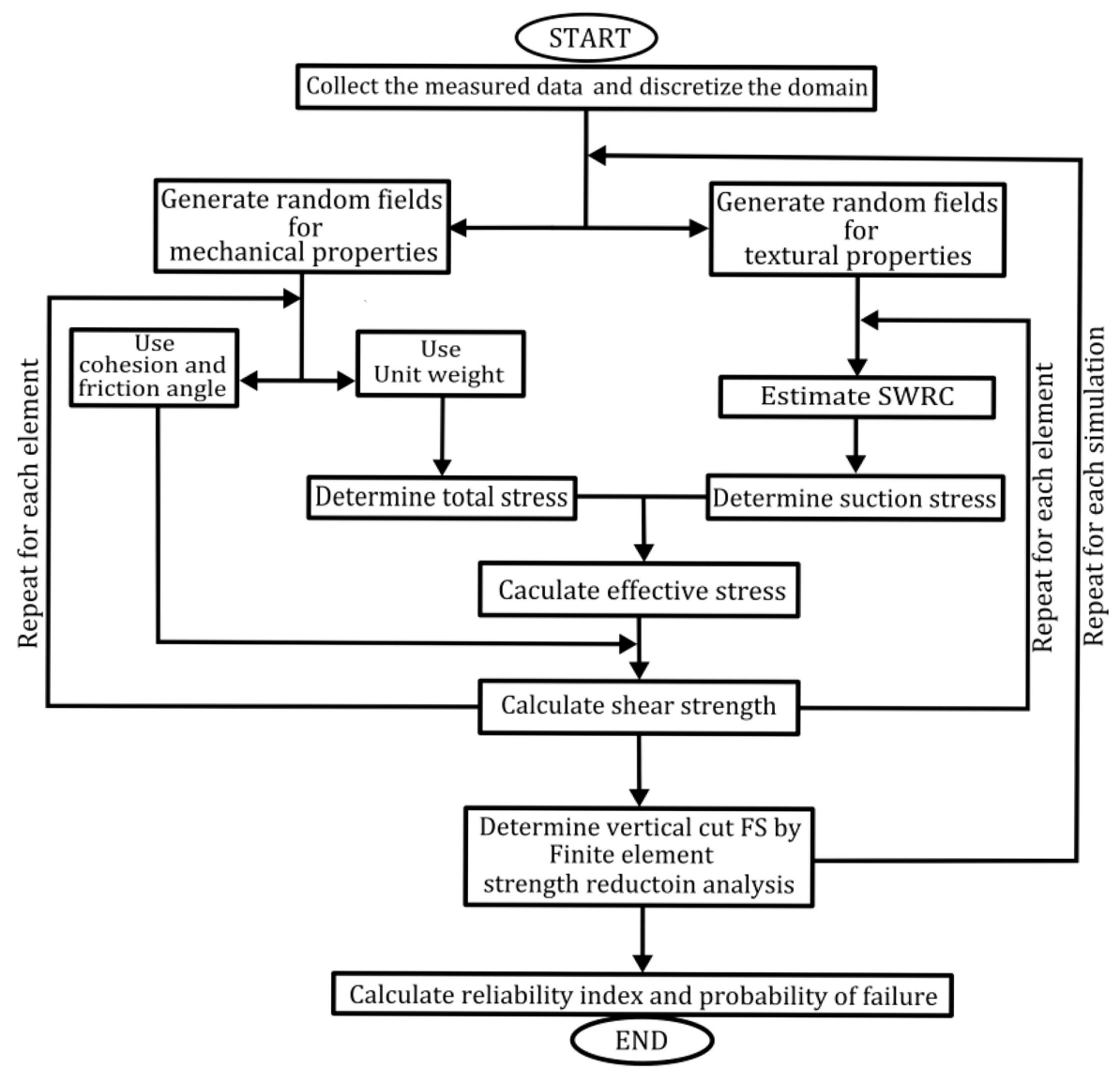

Figure 2. Flowchart of reliability analysis of the vertical cut in unsaturated soils. 
Step 2. Generate conditional random fields using SGS for textural properties (clay content, fine-grained content, gravel content, water content, and bulk density) and also mechanical properties (cohesion, friction angle, and unit weight) of the soil;

Step 3. For each element:

a) Fit a continuous function to the GSD data (i.e., clay content, fined-grained content, and gravel content);

b) Estimate the SWRC from GSD using bulk density value;

c) Determine the suction stress by SWRC and water content value;

d) Calculate the effective stress using the determined suction stress and total stress;

e) Calculate the shear strength by cohesion and friction angle values.

Step 4. Perform finite element strength reduction analysis to obtain the corresponding FS;

Step 5. Repeat Steps 2 to 4 as many as the number of simulations to calculate the probability of failure of vertical cut using MCS.

\section{Case study}

In this section, a case study of a vertical cut in the unsaturated soil is presented to investigate the efficiency of the proposed approach and verification of the coded program. At first, the stability analysis was performed deterministically using FEM without considering unsaturated condition. Then, the probabilistic analysis of the unsaturated vertical cut was conducted by considering uncertainties.

\subsection{Site location and geotechnical soil properties}

The stability analysis of a vertical cut requires the definition of domain geometry, water table level, and shear strength parameters. In this research, these data were prepared based on site investigation.

The site is in Shiraz City in Fars Province of Iran, located in an urban area on satellite overview, as can be seen in Figure 3. The main reason for selecting the site was that the vertical cut mostly consisted of fine-grained soil. In this type of soil, suction plays a more significant role in the stability analysis of soil systems. Moreover, the site consists of two types with quite different soil properties, which could challenge the efficiency and application of the proposed approach in non-homogeneous soils.

To explore the subsurface layers, three boreholes

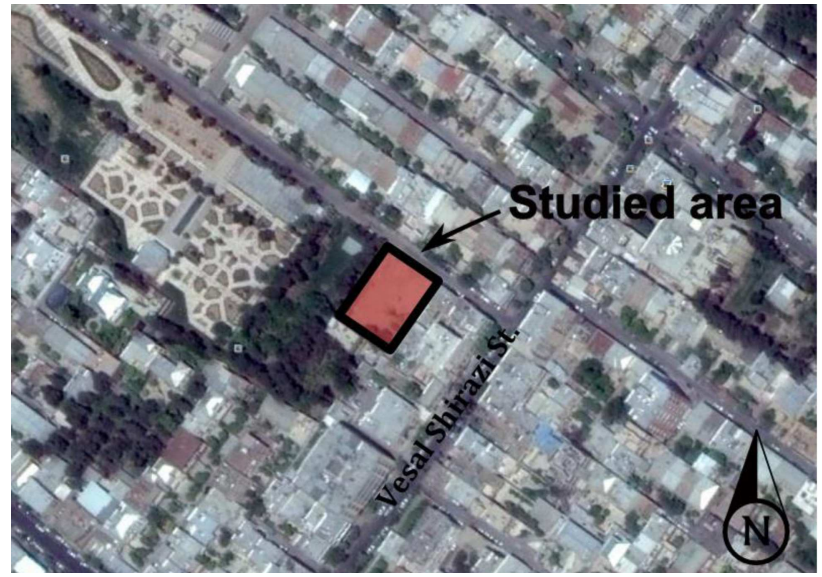

Figure 3. Satellite overview of site location.

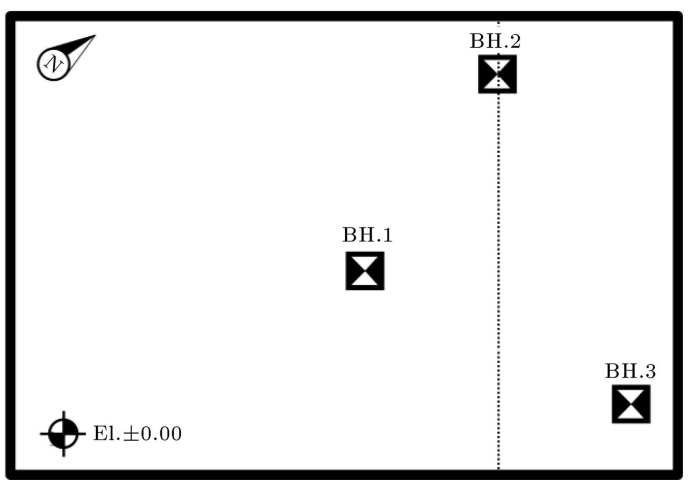

Figure 4. Boreholes arrangement plan.

were drilled to the depth of $16 \mathrm{~m}$ from the natural ground surface. The boreholes arrangement and the ground elevation are presented in Figure 4. For each borehole, the field test (i.e., Standard Penetration Test, SPT) and laboratory tests (i.e., grain size analysis, Atterberg limits tests, and so on) were performed. The borehole database is given in Tables 1 to 3 . The groundwater was not observed after drilling to the depth of $16 \mathrm{~m}$.

In this case study, bulk samples of soil were taken from every two meters of boreholes, and the grain size analysis, bulk density, and the Atterberg limits were determined for all samples. The shear strength parameters were determined scatteredly in different depths, though. Based on the test results, subsurface formation generally consists of two types of soil texture: coarse-grained soil and fine-grained soil. The coarsegrained soil consisted of poorly graded gravel with silt, and sand (GP-GM) was observed on the surface to a depth of $2 \mathrm{~m}$ (Layer 1) and also within the depth of $14 \mathrm{~m}$ to $16 \mathrm{~m}$ (Layer 3 ). On the other hand, finegrained soil, which generally consisted of low plasticity clay (CL), was observed within the depth of $2 \mathrm{~m}$ to $14 \mathrm{~m}$ between coarse-grained layers (Layers 1 and 2 ). The recommended soil properties for deterministic analysis are summarized in Table 4 . A constant value 
Table 1. Soil properties from BH.1.

\begin{tabular}{ccccccccc}
\hline Depth & SPT & $\begin{array}{c}\text { Water } \\
\text { content } \\
(\boldsymbol{\%})\end{array}$ & $\begin{array}{c}\text { Bulk } \\
\text { density } \\
\left(\mathbf{g r} / \mathbf{c m}^{\mathbf{3}}\right)\end{array}$ & $\begin{array}{c}\text { Friction } \\
\text { angle } \\
(\mathbf{d e g})\end{array}$ & $\begin{array}{c}\text { Cohesion } \\
\left(\mathbf{k N} / \mathbf{m}^{\mathbf{2}}\right)\end{array}$ & $\begin{array}{c}\text { Gravel } \\
\text { content } \\
\mathbf{( \% )}\end{array}$ & $\begin{array}{c}\text { Clay } \\
\text { content } \\
(\boldsymbol{\%})\end{array}$ & $\begin{array}{c}\text { Fine-grained } \\
\text { content } \\
(\boldsymbol{\%})\end{array}$ \\
\hline 2 & $>50$ & 3.22 & 1.75 & 37.00 & 8.00 & 58.07 & 0.00 & 14.84 \\
4 & 9 & 14.80 & 1.55 & - & - & 0.00 & 22.00 & 77.50 \\
6 & 9 & 15.93 & 1.56 & 21.00 & 17.00 & 0.00 & 21.00 & 75.40 \\
8 & 10 & 18.45 & 1.57 & - & - & 0.00 & 20.00 & 81.87 \\
10 & 11 & 17.72 & 1.60 & 23.00 & 19.00 & 0.00 & 19.00 & 76.06 \\
12 & 13 & 16.52 & 1.59 & - & - & 0.00 & 19.50 & 74.59 \\
14 & $>50$ & 11.71 & 1.80 & 34.00 & 9.00 & 33.03 & 0.00 & 19.60 \\
16 & $>50$ & 7.32 & 1.84 & - & - & 33.96 & 0.00 & 20.06 \\
\hline
\end{tabular}

Table 2. Soil properties from BH.2.

\begin{tabular}{ccccccccc}
\hline Depth & SPT & $\begin{array}{c}\text { Water } \\
\text { content } \\
(\boldsymbol{\%})\end{array}$ & $\begin{array}{c}\text { Bulk } \\
\text { density } \\
\left(\mathbf{g r} / \mathbf{c m}^{\mathbf{3}}\right)\end{array}$ & $\begin{array}{c}\text { Friction } \\
\text { angle } \\
(\mathbf{d e g})\end{array}$ & $\begin{array}{c}\text { Cohesion } \\
\left(\mathbf{k N} / \mathbf{m}^{\mathbf{2}}\right)\end{array}$ & $\begin{array}{c}\text { Gravel } \\
\text { content } \\
\mathbf{( \% )}\end{array}$ & $\begin{array}{c}\text { Clay } \\
\text { content } \\
(\boldsymbol{\%})\end{array}$ & $\begin{array}{c}\text { Fine-grained } \\
\text { content } \\
(\boldsymbol{\%})\end{array}$ \\
\hline 2 & $>50$ & 2.36 & 1.74 & - & - & 62.82 & 0.00 & 17.53 \\
4 & 8 & 13.00 & 1.59 & 21.00 & 17.00 & 2.00 & 19.00 & 70.00 \\
6 & 9 & 14.18 & 1.60 & - & - & 0.00 & 19.00 & 77.45 \\
8 & 9 & 16.23 & 1.62 & 22.00 & 21.00 & 0.00 & 20.00 & 78.91 \\
10 & 10 & 17.01 & 1.62 & - & - & 0.00 & 20.00 & 82.57 \\
12 & 15 & 16.68 & 1.63 & 24.00 & 20.00 & 0.00 & 20.00 & 76.42 \\
14 & 19 & 15.34 & 1.65 & - & - & 0.00 & 20.00 & 79.72 \\
16 & $>50$ & 8.07 & 1.82 & - & - & 55.49 & 0.00 & 11.59 \\
\hline
\end{tabular}

Table 3. Soil properties from BH.3.

\begin{tabular}{ccccccccc}
\hline Depth & SPT & $\begin{array}{c}\text { Water } \\
\text { content } \\
(\boldsymbol{\%})\end{array}$ & $\begin{array}{c}\text { Bulk } \\
\text { density } \\
\left(\mathbf{g r} / \mathbf{c m}^{\mathbf{3}}\right)\end{array}$ & $\begin{array}{c}\text { Friction } \\
\text { angle } \\
(\mathbf{d e g})\end{array}$ & $\begin{array}{c}\text { Cohesion } \\
\left(\mathbf{k N} / \mathbf{m}^{\mathbf{2}}\right)\end{array}$ & $\begin{array}{c}\text { Gravel } \\
\text { content } \\
\mathbf{( \% )}\end{array}$ & $\begin{array}{c}\text { Clay } \\
\text { content } \\
\mathbf{( \% )}\end{array}$ & $\begin{array}{c}\text { Fine-grained } \\
\text { content } \\
(\boldsymbol{\%})\end{array}$ \\
\hline 2 & $>50$ & 3.01 & 1.80 & 39.00 & 8.50 & 60.00 & 0.00 & 15.00 \\
4 & 8 & 12.70 & 1.57 & - & - & 11.00 & 17.00 & 77.80 \\
6 & 9 & 14.78 & 1.64 & 23.00 & 26.00 & 0.00 & 20.00 & 82.52 \\
8 & 8 & 17.21 & 1.65 & - & - & 0.00 & 21.00 & 84.65 \\
10 & 13 & 17.69 & 1.65 & 22.00 & 19.00 & 0.00 & 19.00 & 71.03 \\
12 & 14 & 16.87 & 1.67 & - & - & 0.00 & 20.00 & 78.12 \\
14 & 17 & 17.03 & 1.70 & - & & 0.00 & 22.00 & 80.79 \\
16 & $>50$ & 6.14 & 1.90 & 36.00 & 9.00 & 67.84 & 0.00 & 21.57 \\
\hline
\end{tabular}

Table 4. Recommended soil properties for deterministic analysis.

\begin{tabular}{ccccccc}
\hline Layer & $\begin{array}{c}\text { Soil } \\
\text { type }\end{array}$ & $\begin{array}{c}\text { Friction } \\
\text { angle } \\
(\mathbf{d e g})\end{array}$ & $\begin{array}{c}\text { Cohesion } \\
(\mathbf{k P a})\end{array}$ & $\begin{array}{c}\text { Unite } \\
\text { weight } \\
\left(\mathbf{k N} / \mathbf{m}^{\mathbf{2}}\right)\end{array}$ & $\begin{array}{c}\text { Modulus of } \\
\text { elasticity } \\
(\mathbf{k P a})\end{array}$ & $\begin{array}{c}\text { Poisson's } \\
\text { ratio }\end{array}$ \\
\hline 1 & GP-GM & 35 & 8 & 21 & 90000 & 0.25 \\
2 & CL & 23 & 21 & 19 & 30000 & 0.35 \\
3 & GP-GM & 35 & 8 & 22 & 95000 & 0.25 \\
\hline
\end{tabular}


of $2.65 \mathrm{gr} / \mathrm{cm}^{3}$ was considered for particle density for both deterministic and probabilistic analyses.

\subsection{Computer programs and deterministic analysis}

A finite-element-based program was coded in MATLAB to calculate the safety factor of the vertical cut. The program is used for a two-dimensional (2D), plane strain condition using an eight-node quadrilateral element of elastic visco-plastic soil with Mohr-Coulomb failure criterion and a non-associated flow rule. The FS for the vertical cut is defined through the division of the original shear strength parameters by strength reduction factors. The model initially consisted of 1600 elements, which have eight nodes and each node has two degrees of freedom in the horizontal and vertical directions. The boundary conditions are defined by fully restraining the bottom side and horizontally restraining the left and right sides of the soil domain. To model the vertical cut, 240 elements were removed in the excavation area; thus, a finite element model with 1360 elements was used in stability analysis. The general conditions of the vertical cut, such as model geometry, depth of layers, and boreholes location, are shown in Figure 5; the related finite element discretization with boundary conditions is presented in Figure 6 .

The stability analysis was performed deterministically, and the safety factor of 0.95 was obtained for the vertical cut without considering suction in soil. Deformed mesh with magnified displacement and the maximum shear strain of the soil are shown in Figures 7

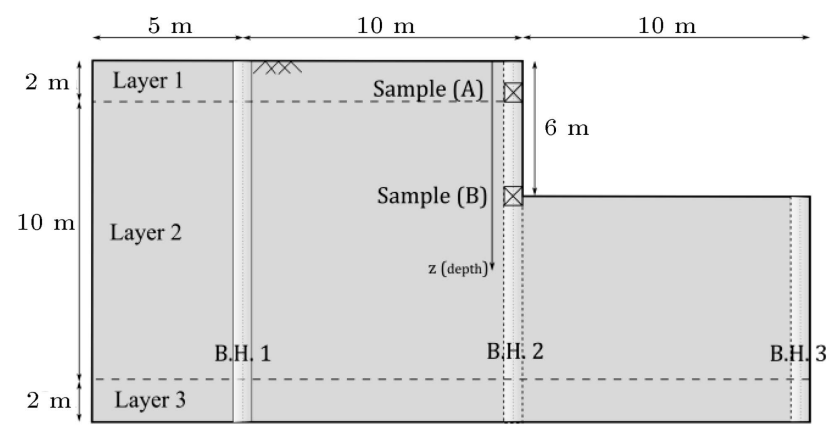

Figure 5. Vertical cut geometry and borehole location.

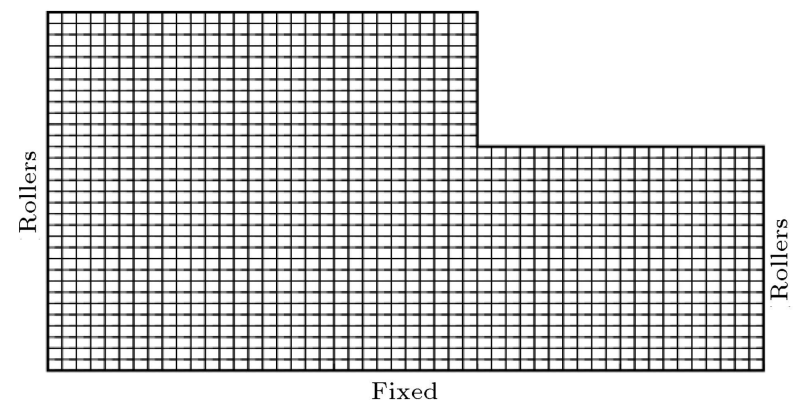

Figure 6. Finite element discretization. and 8, respectively. According to the results, the mechanism is a single-wedge failure with a straight slip surface that starts from the bottom of excavation.

To illustrate the application of suction estimation approach, two samples were selected in different layers, as shown in Figure 5 (Samples A and B). Sample A is located in Layer 1 with coarse-grained soil properties, while Sample B is located in Layer 2 with fine-grained properties. The suction at each element was determined by its SWRC (as explained in Section 1). The SWRC was obtained by PSD through successive summation of pore volumes while PSD itself had been determined by grain size distributions [35]. The grain size distributions and the related SWRC for two samples are presented in Figures 9 and 10, respectively.

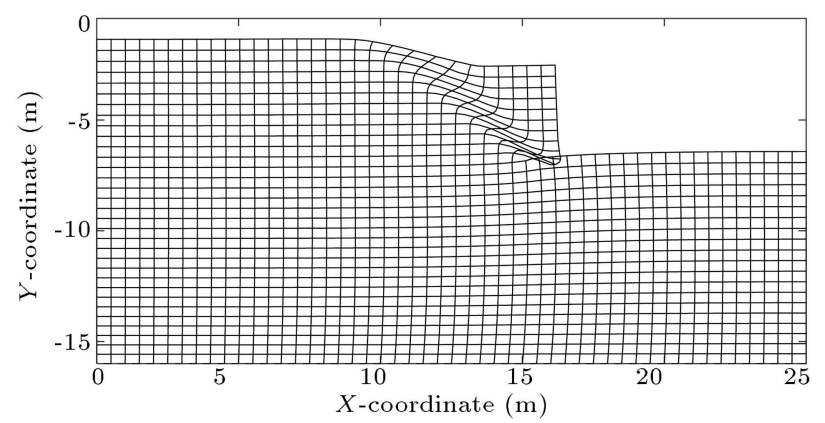

Figure 7. Deformed mesh of the vertical cut.

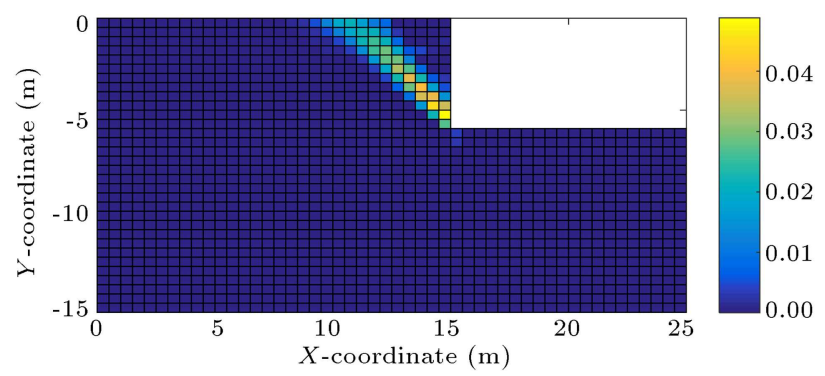

Figure 8. Maximum shear strain of the vertical cut.

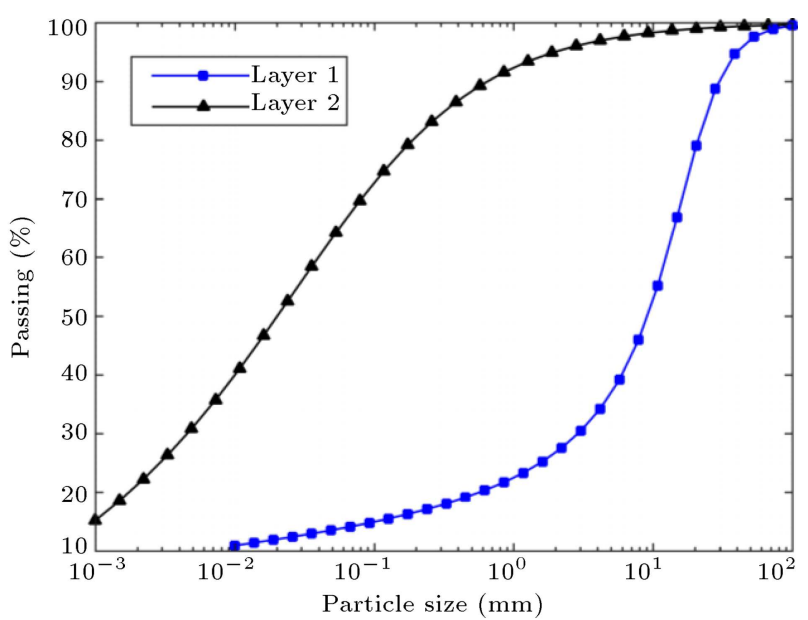

Figure 9. GSD for two samples from BH.2. 


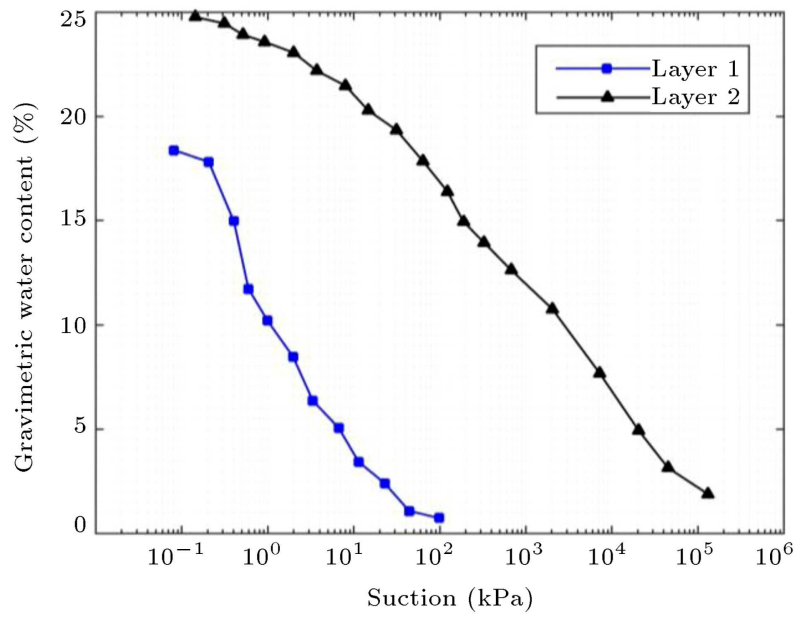

Figure 10. Determined SWRC for two samples from BH.2.

The suction was estimated at samples' locations using obtained SWRC and measured water content as presented in Table 5. In general, higher fine-grained content leads to a higher water retaining ability. The fine-grained soil in Sample A was able to hold much more water at a given potential compared to that in Sample B. This is because of the fine pores and the uniform pore size distribution in fine-grained soils with clay that can hold much more water tenaciously than the relatively large pores in coarse-grained soils. The flat shape of the retention curve for the coarse-grained soil indicates that once the water is drained from the large pores, only a small amount of water will be present [45].

\subsection{Geostatistical analysis of the case study}

To conduct the probabilistic analysis of the unsaturated vertical cut, the uncertainties of SWRC and textural soil properties were considered. To that end, the SWRC estimation's parameters (i.e., bulk density, water content, clay, fine-grained content, and gravel content) and the main mechanical soils' properties (i.e., unit weight, cohesion, and friction angle) were interpolated between the known data through SGS and corresponding semivariograms. The particle density, Poisson's ratio, and modulus of elasticity were considered for deterministic parameters because of their simplicity and small variation over the domain of interest.

In this study, four anisotropic models (i.e., linear, spherical, exponential, and Gaussian) were examined to obtain the best fitting of semivariograms. For this purpose, two statistics were provided to aid the interpolation of model output. The first one is Residual Sums of Squares (RSS) that provides an exact measure of how well the model fits the semivariogram data; the lower the reduced sums of squares are, the better the model fits.

The second one is the coefficient of determination $\left(R^{2}\right)$, which provides an indication of how well the model fits the semivariogram data. Based on these statistics, the exponential model was selected for stochastic parameters because of its accuracy and numerical robustness. For instance, the model's parameters and statistics of bulk density semivariogram are given in Table 6 .

The exponential anisotropic model approaches the sill gradually. However, the model and the sill never actually converge. The formula used for this model is:

$$
\gamma(h)=C_{0}+C(1-\exp (-h / A))
$$

where $C$ is the structural variance $\left(C=S-C_{0}\right), h$ is the lag distance, and $A$ is calculated by the following equation:

$$
A=\sqrt{A_{1}^{2} \cos ^{2}(\beta-\delta)+A_{2}^{2} \sin ^{2}(\beta-\delta)}
$$

In Eq. (27), $A_{1}$ and $A_{2}$ are the range parameters for the major and minor axes, respectively; $\beta$ is the angle between pairs; and $\delta$ is the angle of maximum

Table 5. Estimation of suction in two samples from different layers.

\begin{tabular}{cccc}
\hline & Depth (m) & Water content (\%) & Estimated suction (kPa) \\
\hline Sample A & 2.0 & 2.36 & 20.0 \\
Sample B & 6.0 & 14.18 & 300.0 \\
\hline
\end{tabular}

Table 6. Different semivariogram model parameters for clay content data.

\begin{tabular}{ccccccc}
\hline Model & Nugget & Sill & Range (major) & Range (minor) & RSS & $\boldsymbol{R}^{\mathbf{2}}$ \\
\hline Linear & 0.005 & 0.031 & 38.68 & 38.67 & $5.48 \mathrm{e}-4$ & 0.59 \\
Spherical & 0.004 & 0.030 & 52.61 & 52.06 & $5.48 \mathrm{e}-4$ & 0.60 \\
Gaussian & 0.007 & 0.034 & 26.39 & 26.39 & $5.64 \mathrm{e}-4$ & 0.61 \\
Exponential & 0.004 & 0.037 & 40.29 & 40.28 & $\mathbf{5 . 4 0 e - 4}$ & $\mathbf{0 . 6 6}$ \\
\hline
\end{tabular}




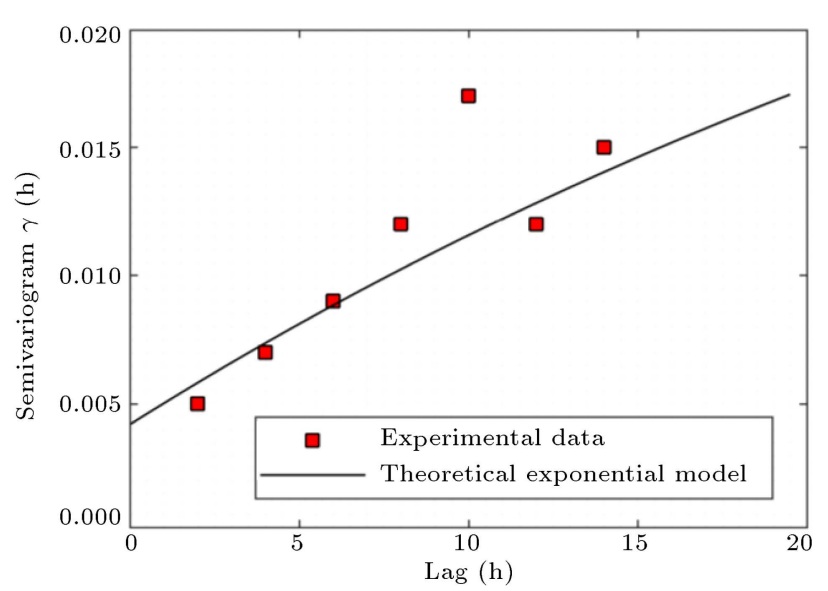

Figure 11. Anisotropic exponential semivariogram model for bulk density.

variation, which is set perpendicular to the horizon in soils. According to the model's parameters in Table 6, the anisotropic exponential semivariogram for bulk density in the vertical direction is presented in Figure 11.

In the geostatistical analysis, it is important to check whether a parameter is related to other parameters, which is a prerequisite for deciding to use kriging or cokriging technique. For this purpose, a regression analysis was performed between all pairs of stochastic parameters, and the correlation coefficient was calculated. There are various kinds of regression techniques, such as linear, logistic, polynomial, and stepwise techniques, available to make predictions. To perform the regression analysis with a feasible amount of computational effort, linear regression was used in this study. As it is expected, the cohesion and friction angle are highly correlated to fine-grained content with correlation coefficients of 0.96 and -0.97 , respectively. Therefore, the cokriging method was used to estimate these two parameters as the primary variables, and fine-grained content was considered as the secondary variable. Other parameters were estimated by the kriging method in the problem domain.

There is another reason for selecting the cokriging method for soil strength parameters, as emphasized in this paper, to make the reliability analysis more efficient. As was mentioned before, the cohesion and the friction angle are undersampled. The limited number of shear strength tests is common in laboratories as a result of time-consuming and excessive cost factors. Hence, there are some missing values in the friction angle and cohesion data at measurement points, as can be seen in Tables 1 to 3 . In this situation, only the information about the undersampled variable is cross-correlated, contained by the other variable. The cokriging method uses this information to improve interpolation estimates without having to sample the primary variable more intensely.

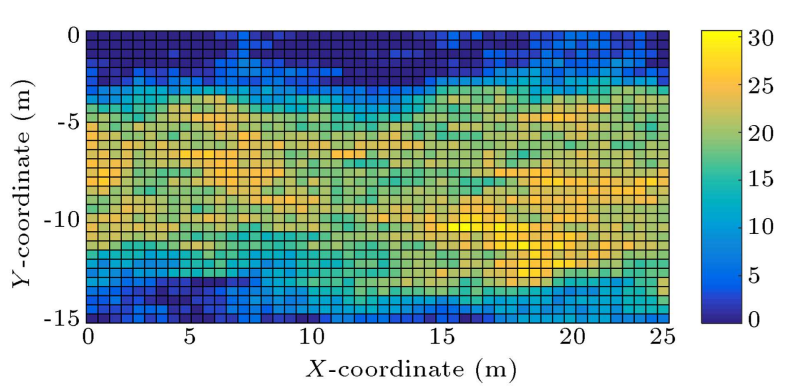

Figure 12. Conditional random field for clay content (\%).

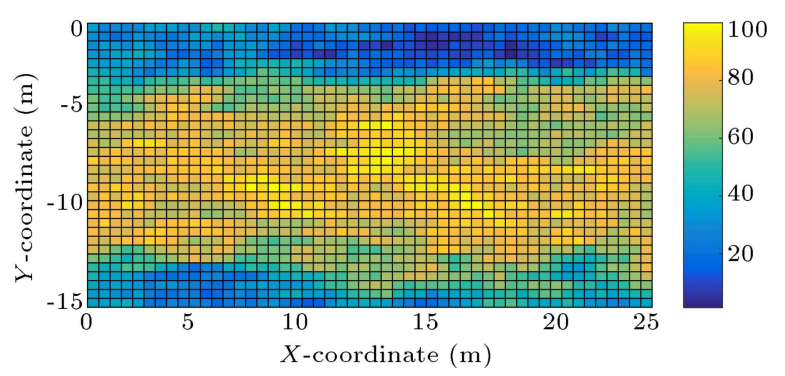

Figure 13. Conditional random field for fine-grained content $(\%)$.

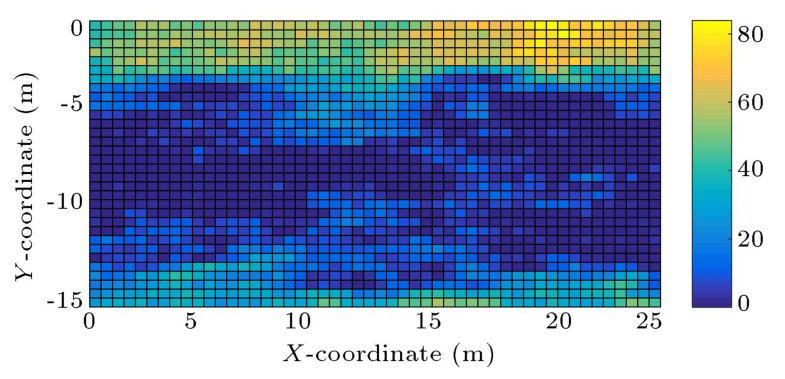

Figure 14. Conditional random field for gravel content $(\%)$.

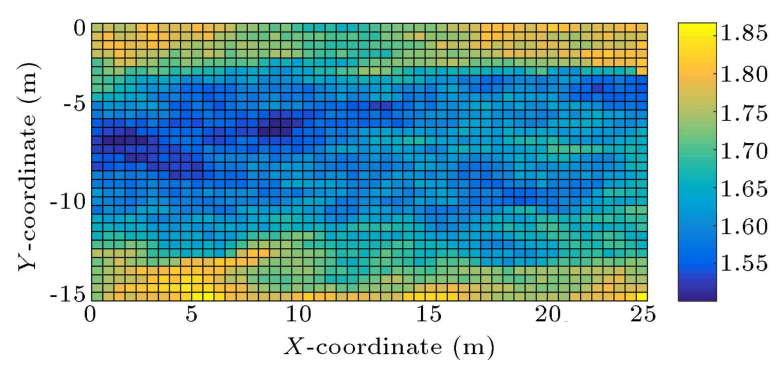

Figure 15. Conditional random field for bulk density $\left(\mathrm{gr} / \mathrm{cm}^{3}\right)$.

In the next step, the conditional random fields were obtained by the SGS procedure. The conditional random fields for stochastic parameters in one realization are shown in Figures 12 to 16 . Figures 12 and 13 illustrate the variation of estimated clay and fine-grained content, which show high values in the middle of the domain (Layer 2), while these parameters reach their minimum at the top and bottom of the domain (Layers 1 and 3 ). The results illustrate good 


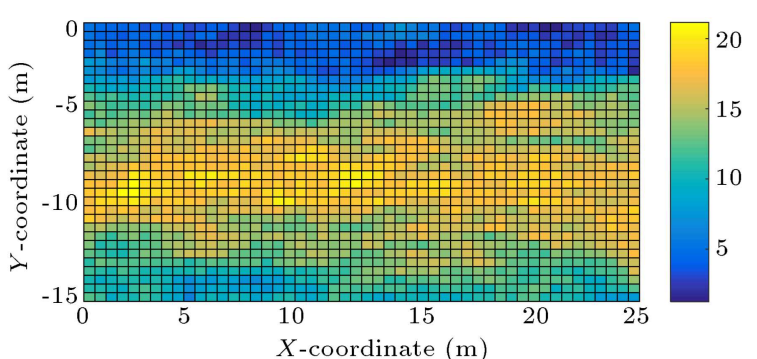

Figure 16. Conditional random field for water content $(\%)$.

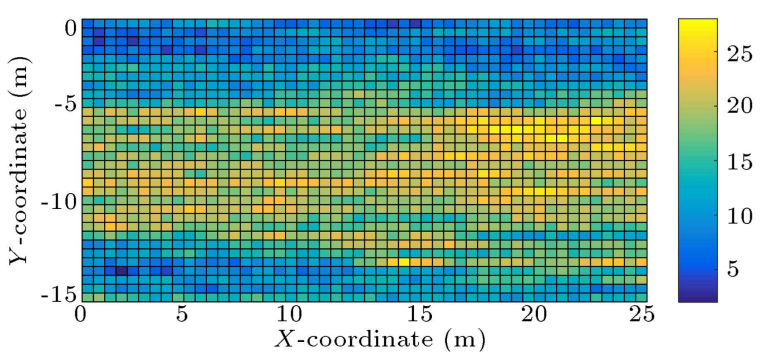

Figure 17. Conditional random field for cohesion $\left(\mathrm{kN} / \mathrm{m}^{2}\right)$.

agreement between estimated values and reported data for boreholes (Tables 1 and 3). Figure 14 presents the estimated gravel content. A good adjustment can be seen between predicted gravel content and measured values (Tables 1 and 3). Figures 15 and 16 show the conditional random fields for bulk density and water content. The results indicate that the values with higher water content are located in Layer 2 where the soil with higher fine-grained content can hold much more water with respect to Layers 1 and 3 . Given the relationship between unit weight and both bulk density and water content, the conditional random field for unit weight was calculated.

The conditional random fields for the cohesion and the friction angle were obtained considering finegrained content as the secondary variable and their cross-semivariogram. It is worth mentioning that the estimation of the cohesion and the friction angle is not only based on the distance to nearby sample location of these parameters, but also on the nearby sample locations for fine-grained content. This can provide a more robust estimate of these two parameters at unsampled locations when they are sufficiently correlated with fine-grained content. Figures 17 and 18 show that the values of the effective cohesion and the effective friction angle stand in inverse relationship to each other. According to Figures 12 to 18, it can be followed that the SGS makes random fields more realistic.

\subsection{Geostatistical simulation verification}

There are some basic checks that should be performed on the geostatistical simulation results. For instance,

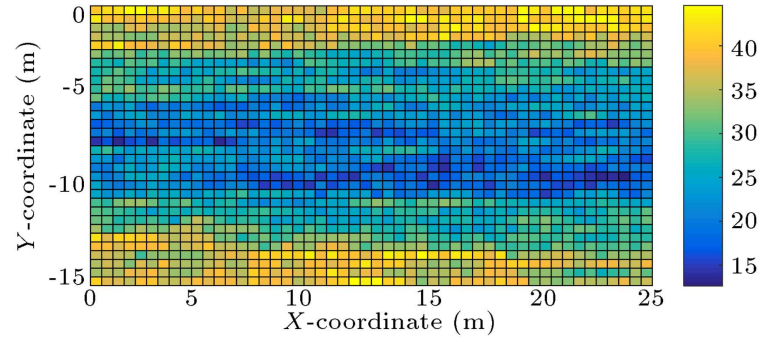

Figure 18. Conditional random field for friction angel (deg.).

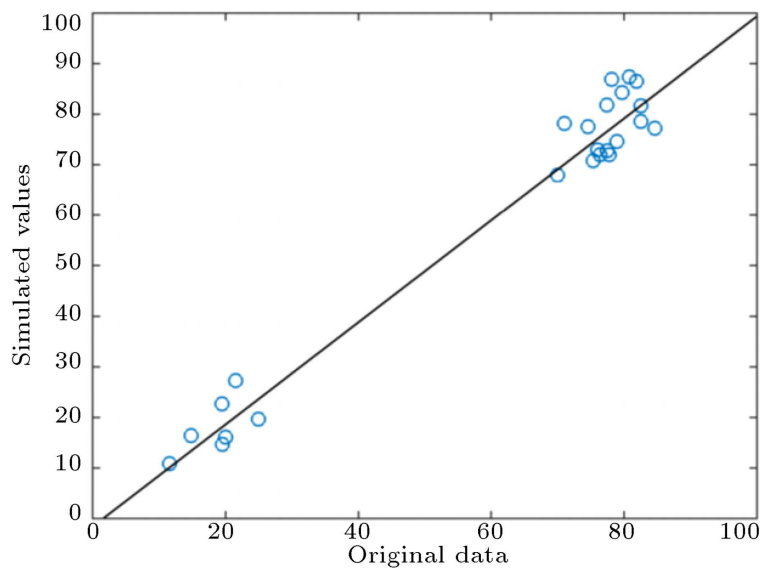

Figure 19. Cross plot of the original data and simulated values for fine-grained content.

all numerical simulations must reproduce data values at their locations, and the spatial continuity is characterized by the semivariogram model [46]. To verify that all data are reproduced at their locations, a cross plot of the data and the simulated values at the nearest elements were generated. Figure 19 shows the cross plot for a realization of fine-grained content between original data and simulated values. Because the samples do not have the same coordinates as central elements, the corresponding cross plot shows slight deviations from the 45-degree line with a high correlation of 0.97 .

For the second basic check, the input semivariogram model should be reproduced within an acceptable fluctuation range. For this purpose, the semivariogram was calculated for multiple realizations and was compared with the input model in the same directions. Semivariogram reproduction depends on a number of interrelated factors such as grid spacing, range of the semivariogram model, size of the field, size of the search neighborhood, and the number of conditioning data [44]. To attenuate the effect of fluctuations, 400 realizations were considered, and 400 corresponding semivariograms were averaged. Figure 20 shows the reproduction of the vertical semivariogram model for fine-grained content. It can be seen that there is a small difference between the input model and the averaged 


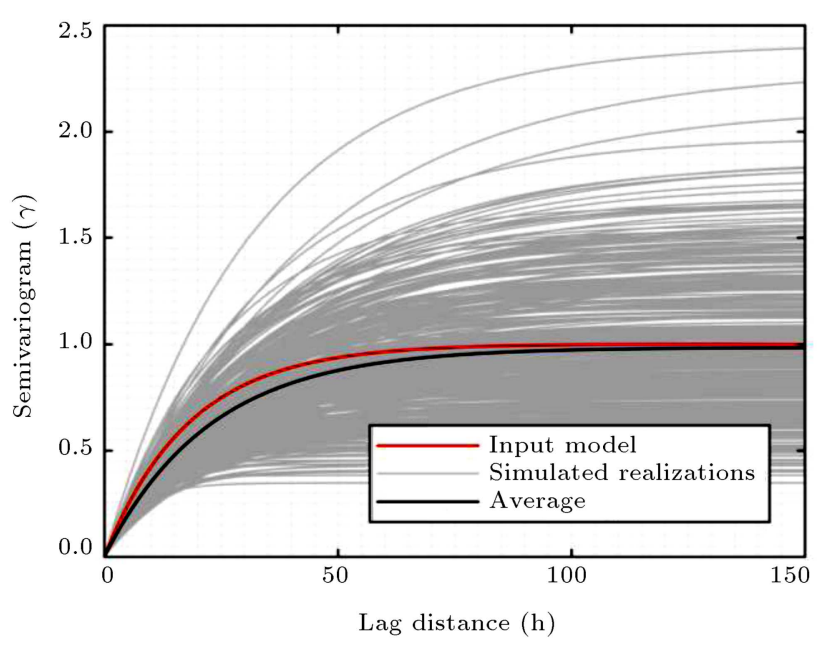

Figure 20. Reproduction of semivariogram for fine-grained content.

semivariogram. This situation can be corrected such that as the field becomes larger with regard to the range, the number of data retained increases, and these data span a larger range of distances [47].

\section{Results and discussion}

Factors of safety provide a quantitative indication of stability analysis. A value of $F S=1.0$ indicates that a problem is on the boundary between stability and instability. Because the quantities involved in computing factors of safety are always uncertain to some degree, computed values of $F S$ are never absolutely precise. Hence, larger factors of safety are required to ensure (or be sure enough) that a vertical cut will be stable [48]. The reliability index $(\beta)$ is an alternative measure of safety, or reliability, which is uniquely related to the probability of failure $\left(P_{f}\right)$. The value of $\beta$ indicates the number of standard deviations between $F S=1.0$ (failure) and the most likely value for $F S$. Once the shape of pdf is estimated, the reliability index can be determined to assess the failure probability.

To perform the reliability analysis of the vertical cut, the SGS steps are repeated for determining the pdf of safety factor. Figure 21 shows a histogram based on 5,000 solutions from the conditional simulation together with a fitted normal function based on the computed values of the mean and standard deviation. Since the values of the stochastic parameters are assumed to be normal, it seems reasonable to assume that the pdf of $F S$ is also normal. Although objective goodness-of-fit tests can be performed, it is noted here that the normal fit seems reasonable, in brief.

\subsection{Effects of unsaturated condition on PDF}

In the next step, the effects of soil suction on reliability analysis of the vertical cut were assessed. For this purpose, the results of conditional simulation with and

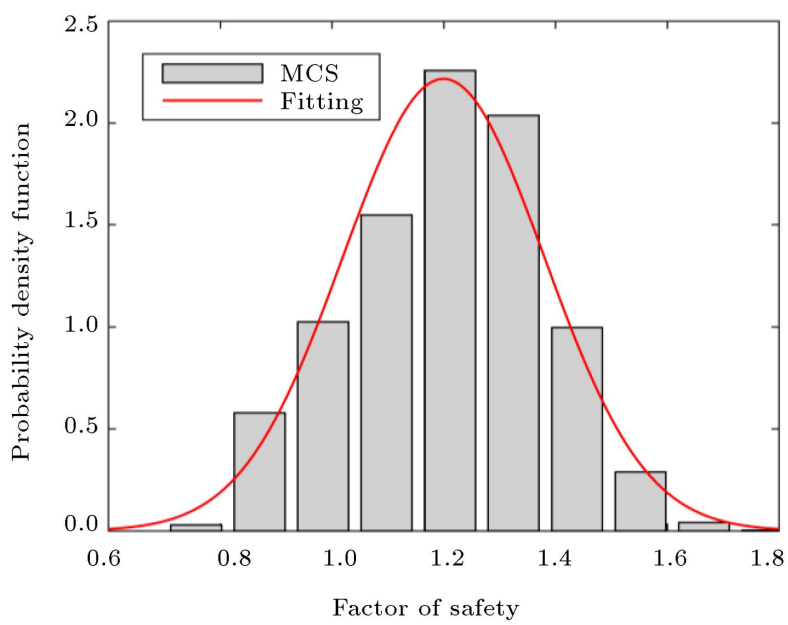

Figure 21. The pdf of safety factor for unsaturated vertical cut based on SGS.

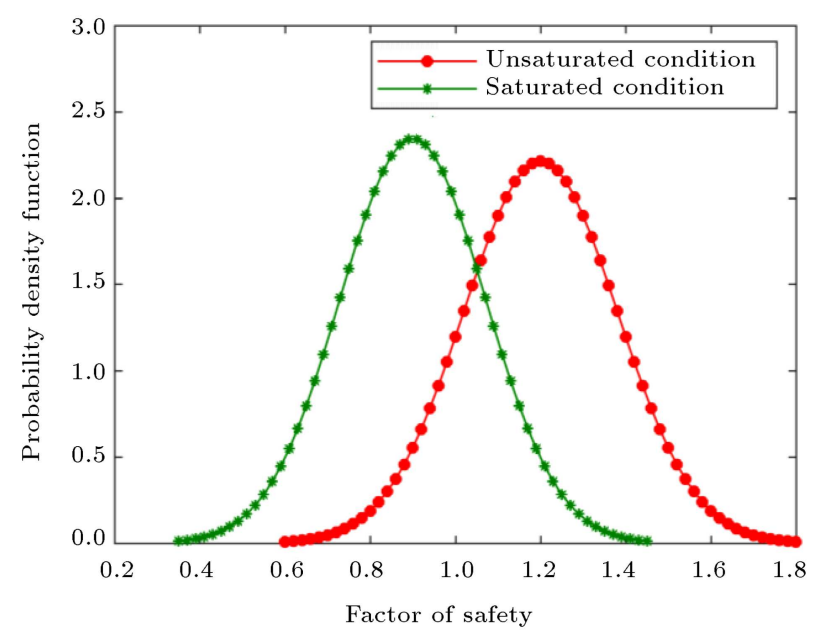

Figure 22. Comparison of safety factor pdf by two conditions.

without considering the suction stress were studied. In the case without considering suction, 5000 conditional fields were generated for stochastic parameters (friction angle, cohesion, and unit weight) in the MCS to determine the pdf for $F S$. The comparison made between the obtained pdf and the calculated pdf from conditional simulation for the unsaturated vertical cut is shown in Figure 22. It can be realized that considering unsaturated condition shifts the mean of pdf from unsafe to safe ranges and changes the sign of reliability index from negative to positive. To compare the failure probabilities of the two conditions, the cumulative density functions (cdfs) of them are plotted in Figure 23. According to this figure, the probability that the $F S$ takes on a value equal to or less than 1.0 is $14 \%$ and $0.72 \%$ for unsaturated and saturated conditions, respectively. This means that standard deviation, reliability index, and probability of failure of the saturated and unsaturated vertical cuts are given in Table 7. 
Table 7. Statistical parameters of pdfs for saturated and unsaturated conditions.

\begin{tabular}{ccccc}
\hline Condition & $\begin{array}{c}\text { Mean } \\
(\boldsymbol{\mu})\end{array}$ & $\begin{array}{c}\text { Standard deviation } \\
(\boldsymbol{\sigma})\end{array}$ & $\begin{array}{c}\text { Reliability index } \\
(\boldsymbol{\beta})\end{array}$ & $\begin{array}{c}\text { Probability of failure } \\
\left(\boldsymbol{P}_{\boldsymbol{f}}\right)\end{array}$ \\
\hline Saturated & 0.90 & 0.17 & -0.59 & 0.72 \\
Unsaturated & 1.20 & 0.18 & 1.11 & 0.14 \\
\hline
\end{tabular}

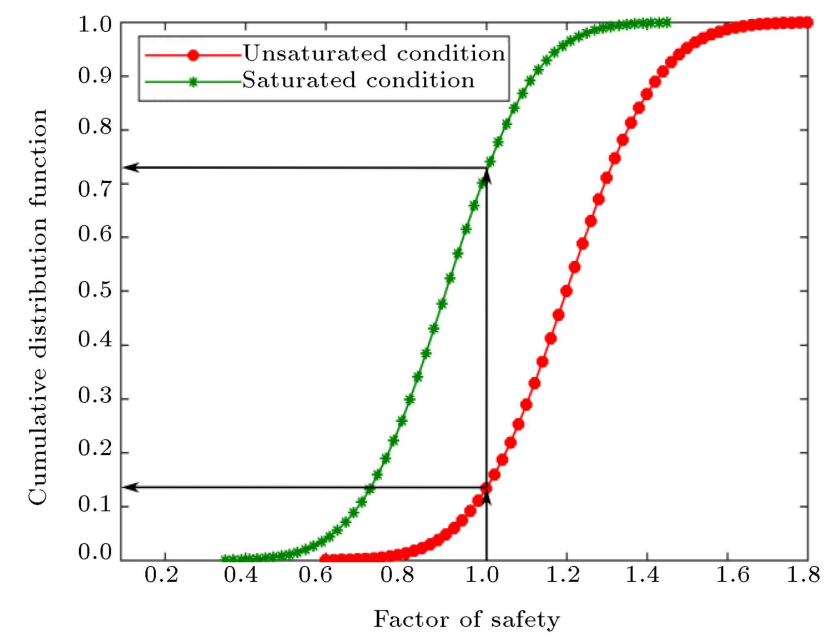

Figure 23. Comparison of failure probability of the vertical cut between the two conditions.

\subsection{Effects of the number of borehole on the probability of failure}

To assess the effect of the number of boreholes on reliability analysis, probabilities of failures for seven cases were determined. For this purpose, in each case, specific numbers of boreholes were considered, as presented in Table 8. Cases 1 to 3 include only one of the boreholes; Cases 4 to 6 include data considering two boreholes, and all data from three boreholes were used in Case 7. Figure 24 shows the probability of failures with regard to the cases determined by the proposed conditional simulation technique for the unsaturated vertical cut. As can be seen in this figure, the probability of failure considerably depends on the layout and the number of boreholes. In other words, the number of known data affects the construction of conditional random fields and inevitably leads to different probabilities of failure. Furthermore, as expected, an increase in the number of known data (the number of boreholes) results in more reliable safety factors of the vertical cut. In line with the obtained results shown in Figure 24, the extracted data from one borehole alone cannot lead to a real failure probability of the site.

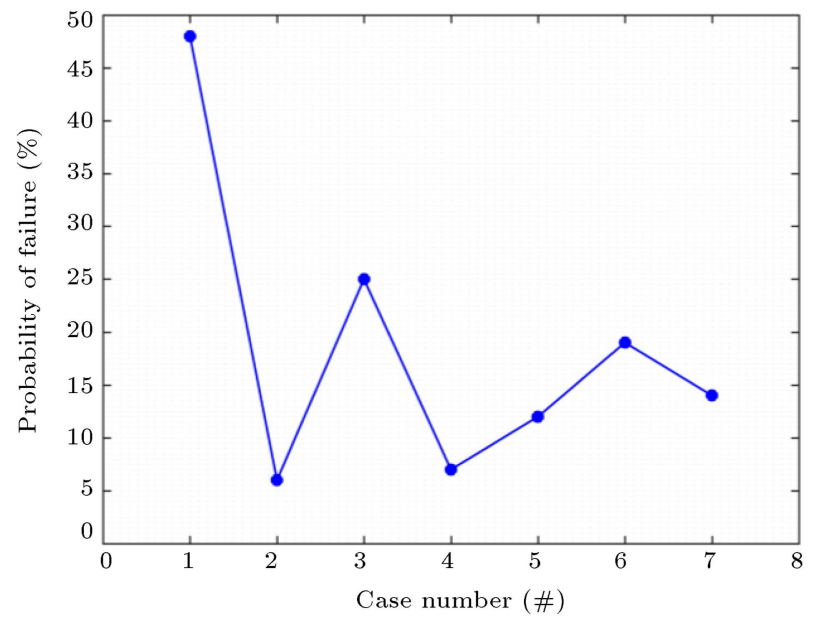

Figure 24. Effect of the number of boreholes on probability of failure.

\section{Conclusion}

In this paper, the finite element method was used in conjugation with geostatistical techniques to perform the reliability analysis of the vertical cut in unsaturated soil. For this purpose, a program was coded in MATLAB.

The soil texture and mechanical properties were conditionally simulated between the known data by using SGS. Since the soil strength parameters are often undersampled, the cokriging method was used to estimate cohesion and friction angle based on not only the distance to the nearby sample location of these parameters, but also the nearby sample locations for fine-grained content. Other stochastic parameters were estimated by using the kriging method.

In order to predict the unsaturated soil behavior, the SWRC was estimated by using physico-empirical method to determine suction stress in effective stress expression. After calculating the effective stress, it was substituted into the shear strength formula to illustrate the failure criteria for unsaturated stability analysis.

To assess the effects of soil suction, the reliability analysis of the vertical cut was conducted with and without considering suction and, then, the cdf of these

Table 8. The number of boreholes considered in the analysis.

\begin{tabular}{ccccccc}
\hline Case $\mathbf{1}$ & Case 2 & Case 3 & Case $\mathbf{4}$ & Case 5 & Case 6 & Case 7 \\
\hline BH.1 & BH.2 & BH.3 & BH.1 and BH.2 & BH.2 and BH.3 & BH.1 and BH.3 & All \\
\hline
\end{tabular}


two different conditions was compared. It is concluded that considering unsaturated condition shifts the mean of pdf from the unsafe to the safe ranges and changes the sign of reliability index from negative into positive. In other words, discarding the unsaturated condition leads to conservative stability design for vertical cuts.

In another part of this paper, the effect of the number of boreholes on the reliability analysis was investigated, and different cases were studied. It is illustrated that the probability of failure considerably depends upon the layout and the number of boreholes. In other words, the number of known data affects the construction of conditional random fields and leads to different probabilities of failure. Furthermore, it is concluded that the data extracted from a borehole alone cannot lead to a real failure probability of the site.

The proposed approach provides a comprehensive reliability analysis of unsaturated soil by using available soil properties. Hence, this reliability approach could be used in any unsaturated geotechnical problems such as foundations, earth retaining structure, and slopes, where the routine soil reports are available.

It is worth noting that the effects of stress history, fabric, confinement, and hysteresis were not addressed in the prediction of unsaturated soil behavior. Moreover, the MCS was used in conjugation with geostatistical techniques to perform the reliability analysis. This numerical simulation is probably the best available tool for evaluating uncertainty in model predictions. However, high time-consumption and massive computational cost are the limitations of this model. Hence, further research is required to study the application of the proposed approach by employing more advanced methods for suction estimation and numerical probability analysis.

\section{References}

1. Mostyn, G.R. and Soo, S. "The effect of autocorrelation on the probability of failure of slopes", 6th Australia, New Zealand Conference on Geomechanics: Geotechnical Risk, pp. 542-546 (1992).

2. Griffiths, D.V. and Fenton, G.A. "Seepage beneath water retaining structures founded on spatially random soil”, Géotechnique, 43(4), pp. 577-587 (1993).

3. Griffiths, D.V. and Fenton, G.A. "Probabilistic slope stability analysis by finite elements", Journal of Geotechnical and Geoenvironmental Engineering, 130(5), pp. 507-518 (2004).

4. Szynakiewicz, T., Griffiths, D.V., and Fenton, G.A. "A probabilistic investigation of $c^{\prime}, \varphi^{\prime}$ slope stability", Proc. 6th Int. Cong. Numerical Methods in Engineering and Scientific Applications, pp. 25-36 (2002).
5. Chong, P.C., Phoon, K.K., and Tan, T.S. "Probabilistic analysis of unsaturated residual soil slopes", Applications of Statistics and Probability (ICASP 7), Rotterdam: Balkema, pp. 375-382 (2000).

6. Tung, Y.K. and Chan, G.C.C. "Stochastic analysis of slope stability considering uncertainties of soil water retention characteristics", Proc. 9th Int. Conf. on Application of Statistics and Probability in Civil Engineering, San Francisco 2, pp. 1409-1414 (2003).

7. Arnold, P. and Hicks, M.A. "Stochastic modelling of unsaturated slope stability", Fifth International Conference on Unsaturated Soils (UNSAT), Barcelona, Spain, pp. 1237-1242 (2010).

8. Arnold, P. and Hicks, M.A. "A stochastic approach to rainfall-induced slope failure", Third International Symposium on Geotechnical Safety and Risk (ISGSR), Munich, Germany, pp. 107-115 (2011).

9. Kim, M.J. and Sitar, N. "Reliability approach to slope stability analysis with spatially correlated soil properties", Soils and Foundations, 53(1), pp. 1-10 (2013).

10. Liu, L.L., Cheng Y.M., and Zhang, Sh., H. "Conditional random field reliability analysis of a cohesionfrictional slope", Computers and Geotechnics, 82, pp. 173-186 (2017).

11. Feuerharmel, C., Bica, A.V.D., Gehling, W.Y.Y., and Flores, J.A. "A study of the shear strength of two unsaturated colluvium soils", Int. Sym. on Adv. Exp. Unsat. Soil Mech., Trento, Italy, pp. 169-174 (2005).

12. Nam, S., Gutierrez, M., Diplas, P., and Petrie, J. "Determination of the shear strength of unsaturated soils using the multistage direct shear test", Eng. Geol., 122(3-4), pp. 272-280 (2011).

13. Fredlund, D.G., Morgenstern, N.R., and Widger, R.A. "Shear strength of unsaturated soils", Can. Geotech. J., 15(3), pp. 313-321 (1978).

14. Corney, D., Coleman, J.D., and Black, W.P.M. "Movement and distribution of water in soil in relation to highway design and performance", Proceedings of the Thirty-Seventh Annual Meeting of the Highway Research Board, pp. 226-252 (1958).

15. Jennings, E. "A revised effective stress law for use in prediction of the behavior of unsaturated soils", Pore Pressure and Suction in Soils Conference, London, pp. 26-30 (1961).

16. Fredlund, D.G., Morgenstern, N.R., and Widger, R.A., "The shear strength of unsaturated soils", Canadian Geotechnical Journal, 15(3), pp. 313-321 (1978).

17. Bishop, A.W., The Principle of Effective Stress, Teknisk Ukeblad (1959).

18. Vanapalli, S. and Fredlund, D. Comparison of Different Procedures to Predict Unsaturated Soil Shear Strength, Geotechnical special publication, pp. 195-209 (2000).

19. Russell, A.R. and Khalili, N. "A unified bounding surface plasticity model for unsaturated soils", International Journal for Numerical and Analytical Methods in Geomechanics, 30(3), pp. 181-212 (2006). 
20. Johari, A., Nakhaee, M., and Habibagahi, G. "Prediction of unsaturated soils effective stress parameter using gene expression programming", Scientia Iranica, 20(5), pp. 1433-1444 (2013).

21. Vanapalli, S.K., Fredlund, D.G., Pufahl, D.E., and Clifton, A.W. "Model for the prediction of shear strength with respect to soil suction", Canadian Geotechnical Journal, 33(3), pp. 379-392 (1996).

22. Cho, S.E. and Lee, S.R. "Instability of unsaturated soil slopes due to infiltration", Computers and Geotechnics, 28(3), pp. 185-208 (2001).

23. Collins, B.D. and Znidarcic, D. "Stability analyses of rainfall induced landslides", Journal of Geotechnical and Geoenvironmental Engineering, 130(4), pp. 362372 (2004).

24. Griffiths, D.V. and Lu, N. "Unsaturated slope stability analysis with steady infiltration or evaporation using elasto-plastic finite elements", International Journal for Numerical and Analytical Methods in Geomechanics, 29(3), pp. 249-267 (2005).

25. Taormina, R. and Chau, K.W. "Data-driven input variable selection for rainfall-runoff modeling using binary-coded particle swarm optimization and extreme learning machines", Journal of Hydrology, 529(3), pp. 1617-1632 (2015).

26. Wu, C.L., Chau, K.W., and Fan, C. "Prediction of rainfall time series using modular artificial neural networks coupled with data preprocessing techniques", Journal of Hydrology, 389(1-2), pp. 146-167 (2010).

27. Chau, K.W. and Wu, CL. "A hybrid model coupled with singular spectrum analysis for daily rainfall prediction", Journal of Hydroinformatics, 12(4), pp. 458473 (2010).

28. Aubertin, M., Ricard, J.F., and Chapuis, R.P. "A predictive model for the water retention curve: application to tailings from hard-rock mines", Canadian Geotechnical Journal, 35(1), pp. 55-69 (1998).

29. Tomasella, J. and Hodnett, M.G. "Estimating soil water retention characteristics from limited data in Brazilian Amazonia", Soil Science, 163(3), pp. 190202 (1998).

30. Arya, L.M. and Paris, J.F. "A physicoempirical model to predict the soil moisture characteristic from particlesize distribution and bulk density data1", Soil Science Society of America Journal, 45(6), pp. 1023-1030 (1981).

31. Zapata, C.E., Houston, W.N., Houston, S.L., and Walsh, K.D. "Soil-water characteristic curve variability", Proceedings of Sessions of Geo-Denver 2000 Advances in Unsaturated Geotechnics, GSP, 99(287), pp. 84-124 (2000).

32. Fredlund, M.D., Wilson, G.W., and Fredlund, D.G. "Use of the grain-size distribution for estimation of the soil-water characteristic curve", Canadian Geotechnical Journal, 39(5), pp. 1103-1117 (2002).
33. Johari, A. and Javadi, A.A. "Prediction of soil water characteristics curves using SPSS", Proceedings of the Fifth Asia-Pacific Conferences on Unsaturated Soils, 1, pp. 345-350 (2011).

34. Johari, A., Habibagahi, G., and Ghahramani, A. "Prediction of soil-water characteristic curve using genetic programming", Journal of Geotechnical and Geoenvironmental Engineering, 132(5), pp. 661-665 (2006).

35. Arya, L.M., Leij, F.J., van Genuchten, M.T., and Shouse, P.J. "Scaling parameter to predict the soil water characteristic from particle-size distribution data", Soil Science Society of America Journal, 63(3), pp. 510-519 (1999).

36. Fredlund, M.D., Fredlund, D.G., and Wilson, G.W. "An equation to represent grain-size distribution", Canadian Geotechnical Journal, 37(4), pp. 817-827 (2000).

37. Zhai, Q. and Rahardjo, H. "Determination of soilwater characteristic curve variables", Computers and Geotechnics, 42, pp. 37-43 (2012).

38. Journel, A.G. and Huijbregts, C.J., Mining Geostatistics, London, Academic Press (1978).

39. Goulard, M. "Inference in a coregionalization model", Geostatistics, Springer, pp. 397-408 (1989).

40. Isaaks, E.H. and Srivastava, R.M., An Introduction to Applied Geostatistics, Oxford University (1989).

41. Matheron, G. "Principles of geostatistics", Economic Geology, 58(8), pp. 1246-1266 (1963).

42. Webster, R. and Oliver, M.A, Geostatistics for Environmental Scientists, John Wiley \& Sons (2001).

43. Fenton, G.A. "Probabilistic methods in geotechnical engineering", ASCE GeoLogan'97 Conference, Logan, Utah, July 15 (1997).

44. Dowd, P.A. "A review of recent developments in geostatistics", Computers and Geosciences, 17(10), pp. 1481-1500 (1991).

45. Brady, N.C.W., Elements of the Nature and Properties of Soils, Pearson (2010).

46. Leuangthong, O., McLennan, J.A., and Deutsch, C.V. "Minimum acceptance criteria for geostatistical realizations", Natural Resources Research, 13(3), pp. 131141 (2004).

47. Tran, T.T. "Improving variogram reproduction on dense simulation grids", Computers \& Geosciences, 20(7), pp. 1161-1168 (1994).

48. Duncan, J.M., Wright, S.G., and Brandon, T.L., Soil Strength and Slope Stability, 2nd Edition, John Wiley \& Sons (2014).

\section{Biographies}

Amir Gholampour was born in 1988 in Shiraz, Iran. He graduated from University of Science and Research of Fars with a Civil Engineering BS degree 
in 2010. He obtained his MS degree in Geotechnical Engineering from Shiraz University of Technology in 2013. Currently, he is furthering his geotechnical engineering education at Shiraz University of Technology as a $\mathrm{PhD}$ candidate. His main research interests include numerical methods in geotechnical engineering, unsaturated soils, and reliability analysis.

Ali Johari obtained his BS, MS, and $\mathrm{PhD}$ degrees in 1995, 1999, and 2006, respectively, from Shiraz
University, Iran, where he is currently an Assistant Professor at the Civil and Environmental Engineering Department. He was a Post-Doctoral Researcher at Exeter University in 2008, where he is also a member of the research staff of the Computational Geomechanics Group. His research interests include unsaturated soil mechanics, application of intelligent systems in geotechnical engineering, probabilistic models, and reliability assessment. He has also consulted and supervised numerous geotechnical projects. 